\title{
Ensino superior e avaliação institucional: um modelo em implantaç̣̃o
}

Bernardete A. Gatti

Palavras-chave: instituição de

ensino superior; avaliação

institucional; modelo de

avaliação; Conselho Estadual

de Educação de São Paulo.

hama a atenção para algumas questões ligadas à cultura de avaliação no Brasil e para aspectos básicos que devem ser considerados quando se realiza um processo avaliativo. Trata esses processos como processos de ajuda, invertendo a visão que comumente se adota para a avaliação. Ressalta o sentido social associado a qualquer processo dessa natureza e as responsabilidades do avaliador. Por fim, apresenta a experiência de avaliação institucional que o Conselho Estadual de Educação de São Paulo vem desenvolvendo com as instituições de ensino superior que estão sob sua jurisdição.

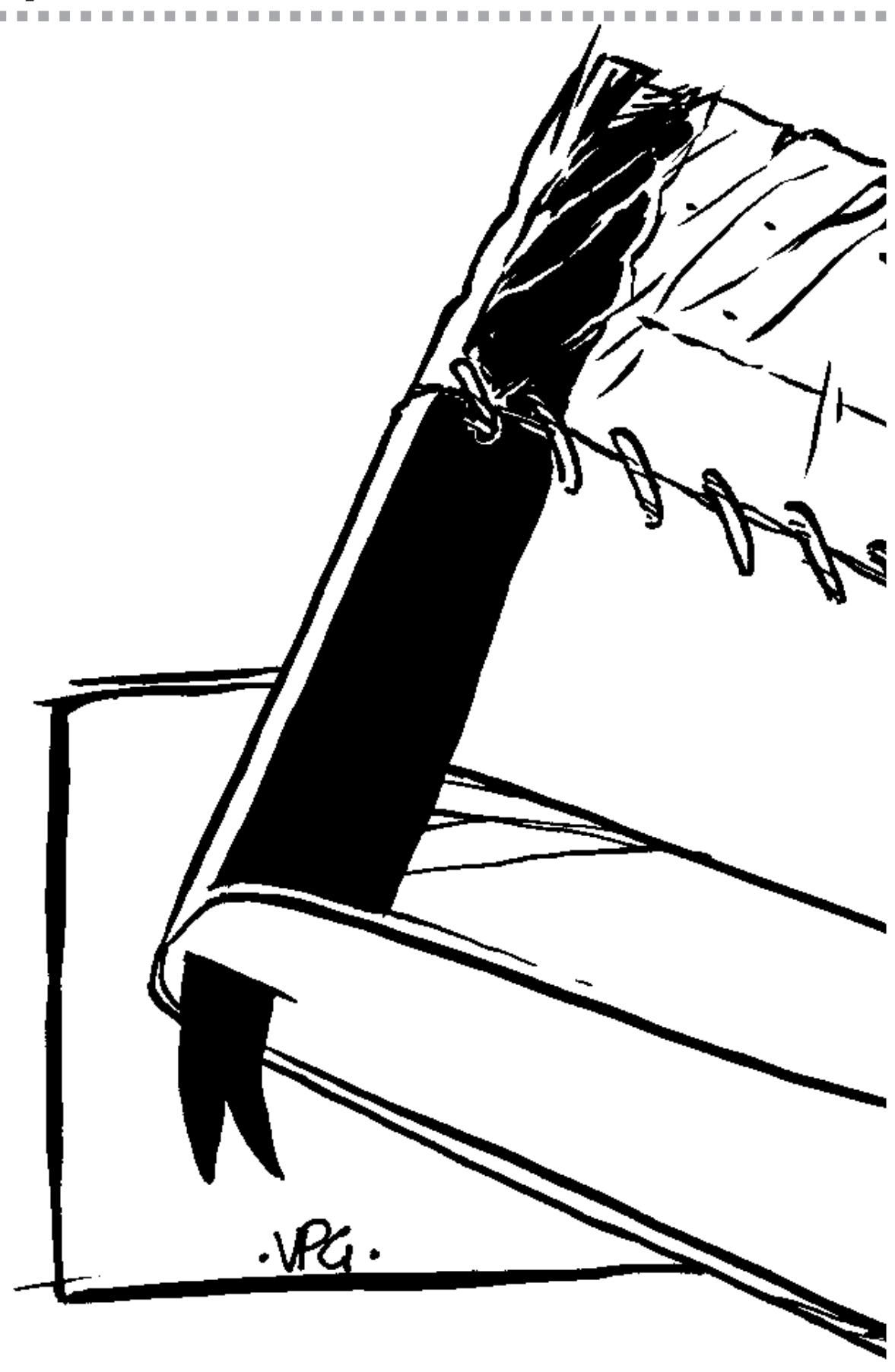




\section{Introdução}

A questão da avaliação de instituições de ensino superior tem sido objeto de inúmeros debates no cenário nacional nos últimos anos. No sistema de ensino do Estado de São Paulo, esses debates também têm sido constantes, alimentando os trabalhos do Conselho Estadual de Educação (CEE), que no Estado de São Paulo têm funções deliberativas no encaminhamento de suas decisões sobre a questão. Consolidou-se em 1999 um modelo de avaliação para as instituições não-universitárias, e, no mesmo espírito e com as mesmas premissas, um modelo para as universidades e centros universitários. Adiante, procuraremos dar uma idéia dos pressupostos que orientam as avaliações propostas, trazendo aspectos dos processos avaliativos que os membros e os técnicos do Conselho Estadual de Educação levaram, e levam em conta no desenvolvimento desses processos, discutindo-os com os avaliadores, depois, apresentaremos o modelo para instituições não-universitárias, e, em seguida, o proposto para as universidades.

\section{Considerações iniciais}

A avaliação é vista na cultura do brasileiro em função de sua história vivida e sofrida, especialmente nos bancos escolares, como punição, reprovação, nãoaceitação. Tememos qualquer tipo de avaliação, não gostamos de ser avaliados. No entanto, usamos processos avaliativos o tempo todo: na vida cotidiana, profissional, familiar, e na vida afetiva. É um processo necessário para a continuidade de nossas ações em todos os níveis da vida. Ao escovar os dentes, estou avaliando simultaneamente a força que aplico na escova para não me machucar; antes de casar, pondero o envolvimento emocional, as condições gerais para isto, etc.; antes de comprar um imóvel, avalio os custosbenefícios, as condições de pagamento. Avaliamos o tempo todo para dar continuidade a nossas ações. Avaliamos antes, durante e depois de nossas ações cotidianas, intuitiva ou organizadamente, mais ou menos conscientemente. Os processos avaliativos são, assim, parte integrante de nosso dia-a-dia, ajudam-nos a processar mudanças, ou a reforçar caminhos 
e rotinas, a cessar ações, etc. Constituemse processos de ajuda em nosso dia-a-dia, e, desse modo, deveriam as avaliações mais sistematizadas ser concebidas e desenvolvidas: a avaliação escolar, a institucional, a de sistemas de ensino, de cursos, de desenvolvimento de projetos, entre tantas outras. Os processos de avaliação devem ser concebidos e executados, não como instrumentos de punição, humilhação, depreciação, mas, sim, como meios de alavancar ações e pessoas, corrigir problemas e solucionar impasses. Por isso, a necessidade de tratar as questões de avaliação com seriedade e transparência, bomsenso e ponderação e, com competência, donde a importância para diferentes profissionais da aquisição de conhecimentos mais aprofundados nessa área. Esta constitui hoje campo de estudo que acumula conhecimentos interessantes, historicamente produzidos, criticados, reformulados, refletidos, aperfeiçoados. Porém, é necessário que mudemos nossa representação e concepções em relação aos procedimentos de avaliação: avaliações são processos que devem gerar estímulo, servir de alavanca, servir à mudança e à transformação, e não serem utilizados para rebaixamento de auto-estima, seletividade, punição, diminuição de valia. Isto está associado aos valores de quem avalia, por que se avalia, como se avalia, para que se avalia, para quem se avalia.

Quando se trata de avaliação que atinge pessoas em suas vidas profissionais e pessoais, há cuidados imprescindíveis a tomar. Envolve questões de ética, além de envolver conhecimento científico e técnico. Não pode ser um processo impensado, feito com ligeireza. É preciso refletir sobre os impactos desse processo, que tem conseqüências pessoais, sociais, institucionais. Os processos avaliativos são os que implicam necessariamente julgamento de valor e necessita de consciência ética em relação aos objetivos, finalidades, procedimentos utilizados, ações decorrentes e seus conseqüentes. Há necessidade de domínio dos fundamentos de diferentes processos e procedimentos de avaliação, um domínio científico e técnico, ao lado de reflexões e cuidados éticos.

Avaliação é, como já foi dito, julgamento de valor, é mais do que simplesmente medir; medir é meio para levantar dados, mas não é avaliação; avaliar é analisar, comparar, relacionar dados para emitir um julgamento sobre eles segundo alguns referentes. Estes referentes devem ser claros tanto para quem avalia como para quem é avaliado. Qualquer modelo de avaliação para ser efetivo deve ter como ponto de partida a realidade do fenômeno a que se refere, inclusive quanto às condições histórico-culturais e sociais. As modernas teorias de avaliação acentuam este aspecto, e os modelos são validados em sua consistência específica, ad hoc. Não há modelos gerais, abstratos, válidos para qualquer condição. Muito menos indicadores. Estes têm que ser construídos por e para um dado contexto, e seu significado se constrói neste contexto. Além disso, para fenômenos humanos, educacionais, propõem-se modelos dinâmicos, com a incorporação das trajetórias de ações, seus laços significativos, seu lastro e seus conseqüentes perceptíveis. A avaliação não pode encastelar-se em pressupostos abstratos, descontextualizados e sem transparência de objetivos.

A avaliação deve ajudar o processo de ampliação das possibilidades humanas, com qualidade crescente e não limitar ou frear potencialidades. Além disso, processos avaliativos só adquirem possibilidade de impacto se considerados valiosos para a comunidade de referência. A valorização e a sustentação de qualquer processo de avaliação dependem, sobretudo, do retorno construtivo dos seus resultados. A não ser que estejamos querendo instituir uma filosofia de competição selvagem, ou criar situações de privilégio a determinados grupos. É preciso ter em mente que nenhum sistema de avaliação é perfeito ou onipotente, e que, também, nenhuma parcela de qualquer comunidade é detentora exclusiva da verdade sobre qualidade. A pergunta, sempre e sempre, ao avaliarmos, é: de quais qualidades falamos? E a questão deve ser posta realmente no plural - qualidades - pois, para diversificadas necessidades e condições, diversificadas qualidades a serem buscadas nos processos avaliativos.

A questão da qualificação, do preparo de quem faz avaliação, é outro aspecto que não pode ser desprezado. Avaliar não é só medir, mensurar, como já dissemos. Se medir bem já é problemático, avaliar o é em dobro. Como processo complexo que exige uma heurística e maturidade no trato de questões pessoais e sociais, além de exercício interdisciplinar, sua implementação 
pede a quem o realiza que tenha exercitado este tipo de reflexão. Não se improvisa um avaliador, como não se improvisa um pesquisador, um médico, um professor. Os próprios professores são pouco preparados para avaliar seus alunos. Em avaliações institucionais, esta questão também não é simples. Este aspecto - o da preparação de quem vai avaliar - não tem sido muito debatido entre nós. Fica-se com a impressão de que qualquer um pode avaliar qualquer coisa. É verdade, no nível do senso comum. Porém, em processos com implicações para a vida de pessoas, implicações sociais, para políticas em diferentes instâncias, é preciso que amadureçamos na preparação para o exercício da avaliação, se a reconhecemos como um meio importante para os processos de transformação humano-sociais.

Levando em conta estas considerações, deu-se andamento aos processos avaliativos institucionais.

\section{Bases da avaliação proposta pelo CEE/SP para as instituições de ensino superior de seu sistema}

De início, é preciso deixar claro que o CEE/SP não tem jurisdição sobre as instituições privadas de ensino superior, mas tem sob sua jurisdição um conjunto relativamente grande de instituições estaduais e municipais que ministram ensino superior. A política desse conselho, nos últimos anos, tem sido de incentivar o desenvolvimento e ampliação da ação dessas instituições, ligadas aos municípios ou ao Estado, mas essa política vem tratando também, com muito cuidado, da questão da qualidade desse ensino. Essa é uma questão que preocupa, visto que todas as avaliações e pesquisas já realizadas até aqui, sobre o nível superior de ensino, mostram bem os problemas que estamos vivendo em relação à formação desenvolvida pelas instituições nesse nível. A política que a Câmara da Educação Superior do CEE/SP vem definindo, através de suas indicações e deliberações, é uma política de busca de melhor qualificação dessas instituições, a partir de uma perspectiva pedagógica.

Dentro desta perspectiva, vem sendo implementado um sistema de avaliação e acompanhamento dessas instituições, com o objetivo de:

explicitar qual o papel social das mesmas, em seu local de atuação, na direção de uma sociedade mais justa, democrática e moderna; ampliar a qualidade do ensino mediante a análise, revisão e reconstrução dos projetos institucionais e educacionais; impulsionar um processo criativo de autocrítica e auto-avaliação; contribuir para a melhoria da qualidade de suas ações educacionais; contribuir para o processo de autorização, credenciamento e reconhecimento de instituições e cursos (Cf. Documento CEE/Reunião com Especialistas Avaliadores, 1998).

É uma perspectiva proativa, com uma concepção de orientação e ajuda às instituições, no sentido de melhorarem seu perfil de desempenho, constantemente, como um todo, no ambiente onde atua e em função das metas que se coloca.

A dinâmica dessa avaliação está diretamente ligada à ênfase da Lei de Diretrizes e Bases da Educação Nacional (LDB) no que se refere ao desenvolvimento, pelos sistemas de avaliações do ensino em todos os níveis, e, às questões do credenciamento e recredenciamento das instituições, autorização e reconhecimento de cursos, e sua renovação periódica de reconhecimento. A LDB, ao colocar o credenciamento e reconhecimento de cursos como atos que exigem renovação periódica, substituindo o reconhecimento perene da legislação anterior, colocou um novo traço característico na política de ensino superior: as instituições precisam atualizarse, qualificar-se em seu tempo para continuar atuando. O papel dos cidadãos, dos usuários do sistema, e o do Estado é agir para garantir a atuação das instituições de ensino superior com eficácia. Sobretudo, estas instituições têm de responder à altura aos desafios postos pela crescente demanda de formação cultural das novas gerações, bem como da profissionalização no contexto de sociedades mutantes. A verificação do cumprimento do papel social, de modo condizente com padrões emergentes dessas instituições, demanda processos avaliativos específicos, periódicos ou continuados, que tenham credibilidade social ampla e não só internamente à instituição.

O CEE/SP, em 1995, fez um exame da situação das instituições municipais de 
ensino superior no Estado de São Paulo, das instituições estaduais isoladas e, das quatro universidades que, até o momento, estão sob a égide deste Conselho - Universidade de São Paulo (USP), Universidade Estadual de Campinas (Unicamp), Universidade Estadual Paulista (Unesp) e Universidade de Taubaté (Unitau). A análise mostrou que tínhamos um sistema com grandes desigualdades em seu desenvolvimento qualitativo, tanto no que se referia a pessoal, como a ensino. Deparamo-nos com aspectos de excelência, inclusive em faculdades isoladas, onde encontramos algumas surpresas muito interessantes; mas, também, deparamo-nos com problemas, por exemplo, de estagnação em currículos e programas, na formação do corpo docente, com a ausência nas instituições de uma política continuada, um projeto, para alavancá-las de um eixo de certa comodidade. A rotina, realmente, às vezes toma conta das instituições, especialmente quando não há desafios externos, ou se não há uma cultura de mobilizar-se continuamente em relação às mudanças e transformações que estão ocorrendo no âmbito social em geral, fora dos muros institucionais.

Há um certo tipo de atenção que todas as instituições de ensino superior devem ter com relação ao que está se passando na sociedade. A sociedade, em sua dinâmica, é o eixo fundamental em relação ao qual as universidades e faculdades precisam estar atentas; não se trata aqui de que a universidade ou a instituição de ensino superior deva viver em função do que se diz quanto ao mercado de trabalho, como muitos propõem. Não é isso. A sociedade é muito mais do que os mercados (de trabalho ou financeiro), além do que, estar-se atento a eles não quer dizer sujeição. Mas, ater-se a esse âmbito é limitado demais. Essa sociedade movente está mostrando que não é só o mercado que comanda as coisas, há atividades, ações, problemas que precisam ser cogitados por essas instituições de ensino superior e que extrapolam o mercado. Mesmo porque têm, também, um papel a desempenhar na direção de abertura de horizontes novos, de transformações sociais que possam ser significativas para a maioria das pessoas. $\mathrm{O}$ que o CEE/SP vem tentando pontuar, em documentos, reuniões e seminários, é que essas instituições precisam ainda se abrir para a sua comunidade próxima, porque elas têm um papel fundamental a exercer ali, em seu lugar de inserção geográfica. Importante, nesta direção, é que definam sua vocação, sua identidade e objetivos socialmente relevantes. Considere-se que esta definição não pode ser feita apenas em nível de dirigentes, como proposta de gabinete, mas sim, a partir de discussões coletivas que envolvam professores, alunos, comunidade pertinente. Atualizar-se constantemente é o mote. Inclusive estamos adentrando um momento em que novas perspectivas curriculares para os cursos estão sendo discutidas. Também, a integração das diferentes instâncias responsáveis pelos cursos superiores é muito importante, caso se queira trabalhar nesse espírito construtivo; reitorias e outros órgãos deliberativos e executivos, direções de autarquias/mantenedoras fundacionais e instituições de ensino superior precisam ter metas coerentemente articuladas e interessadas no desenvolvimento institucional, ao lado de atenção às renovações normativas e às demandas da comunidade. Os processos avaliativos, internos e externos, podem contribuir para isto. Ao se avaliar a instituição como um todo, também se está olhando para essa integração participativa, que é um dos aspectos que se procura estimular.

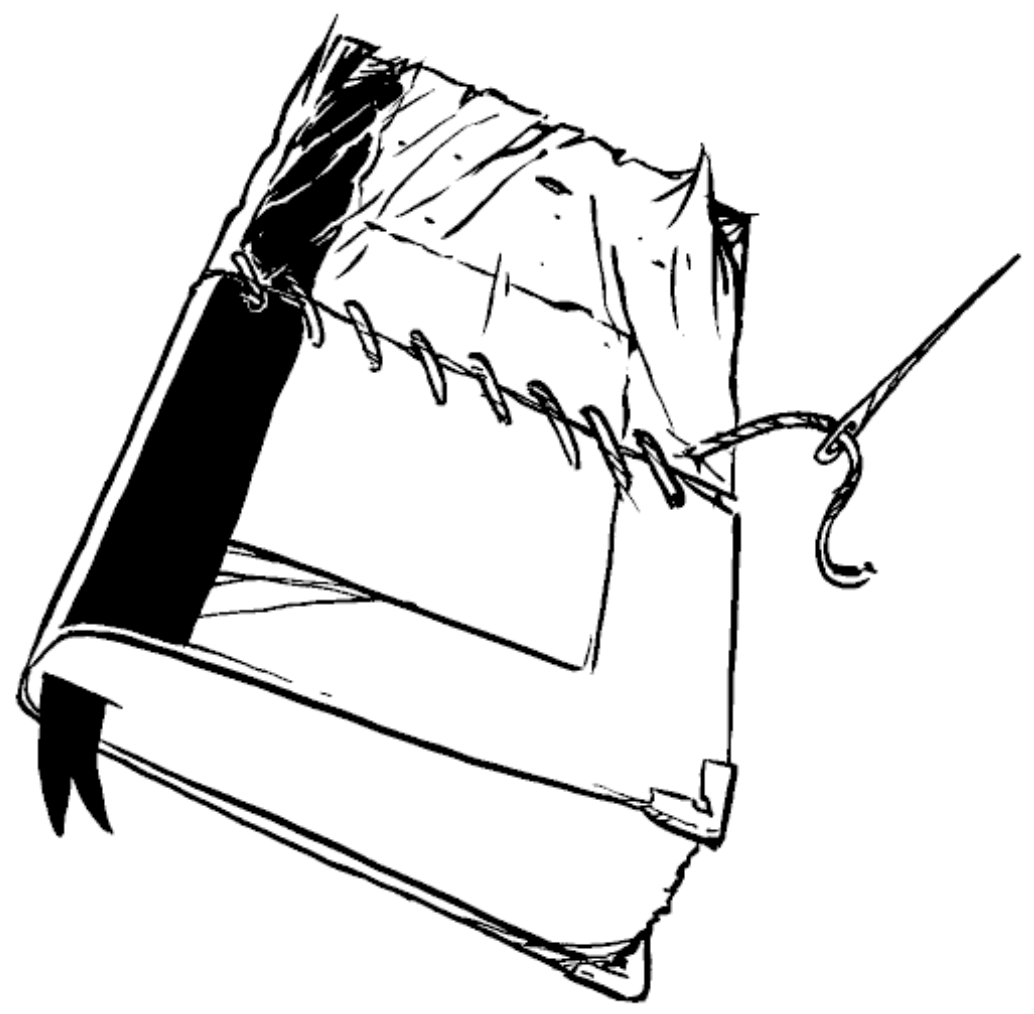




\section{Avaliação das instituições de ensino superior não-universitárias}

A avaliação continuada, proposta pelo CEE/SP para essas instituições, pauta-se pelas premissas acima expostas, e, por isso, optou-se por uma avaliação institucional, que leve em conta a instituição como um todo, em seu contexto. Considera-se nessa avaliação que a atualização e meIhor adequação dos cursos e outras atividades só podem ser desenvolvidas com um corpo docente bem qualificado, uma administração sensível às mudanças necessárias, flexível e participativa, com a disponibilização de uma infra-estrutura adequada para $\mathrm{o}$ atendimento de necessidades básicas para o bom funcionamento dos cursos e atendimento aos alunos, como boas bibliotecas e laboratórios, entre outras condições. Esta avaliação foi, também, concebida como uma avaliação externa, com visita de especialistas, como um processo contínuo, em ciclos. Por essa razão, orientaram-se as instituições a estarem sempre preparadas para receber a comissão externa que irá fazer a avaliação da instituição. Para isto, elas devem constituir seu portfólio com os dados solicitados e outros que queiram agregar e mantê-lo sempre atualizado. Esse portfólio, uma vez estruturado, apenas precisará ir sendo complementado, o que torna o processo de apresentação documental bem mais tranqüilo, ao longo do tempo, e, certamente, mais consistente. Manter seu portfólio em dia (a fotografia institucional), tanto do ponto de vista do projeto pedagógico, dos projetos e planos institucionais, de cadastro de professores, de currículos de professores, de ementas, de bibliografias, etc., não só é importante ante o acompanhamento externo mas, sobretudo, deve ser importante para a própria instituição, seus dirigentes, professores, alunos, funcionários, que, com estas "fotografias" e suas interpretações, poderão acompanhar a dinâmica da instituição onde trabalham, estudam, as boas qualidades e os problemas, criando uma cultura de busca de soluções. O CEE/SP tem explicitado, como meta, que este processo de organização das informações institucionais, sempre atualizadas, analisadas e disponibilizadas, sirva para a criação e sustentação de um processo de auto- avaliação das instituições que desenvolvam, nelas mesmas, a capacidade de reconhecer seus eventuais problemas e de mobilizar-se para a busca coletiva de soluções, sem esperar um alerta de fora, uma demanda externa. Estes procedimentos auto-avaliativos poderão, e muito, contribuir para a avaliação externa, que será feita pelo conselho, e para seu desenvolvimento, e até integrar-se a esta.

O processo de avaliação institucional a que nos referimos aqui segue o seguinte percurso:

1. A instituição prepara a documentação especificada pelo CEE/SP e a consolida num portfólio, que deve ser atualizado constantemente.

2. Dentre os especialistas cadastrados no CEE, todos doutores e com currículo destacado em diferentes áreas de especialidade, são indicados pela Câmara de Educação Superior nomes para compor a comissão externa de consultores, indicação esta que foi submetida à aprovação do Conselho Pleno; cada dupla de avaliadores foi composta por um especialista da área da educação e outro de área diversa, mas com experiência de participação em gestão institucional. O CEE/SP dispõe de um cadastro de consultores, que é constituído basicamente a partir do cadastro de pesquisadores da Fundação de Amparo à Pesquisa do Estado de São Paulo (Fapesp), acrescido de professores indicados por conselheiros, cujos currículos se situam no mesmo patamar dos da listagem inicial; são professores de vários mestrados e doutorados, credenciados pela Fundação Coordenação de Aperfeiçoamento de Pessoal de Nível Superior (Capes), professores titulados com vida ativa em pesquisa, institucional e comunitária. O cadastro de especialistas do CEE/ SP não é baseado em uma única instituição, mas é baseado na competência e no currículo do professor, criteriosamente examinado. Continuando a descrição que fazíamos, as duplas de especialistas que participam da avaliação das instituições são compostas sempre de uma pessoa com formação na área de educação com alguma experiência em avaliação educacional, e outra com diferente formação mas, na condição de ter exercido cargos institucionais ou em comissões científicas diversas que lhe permitisse trânsito maior entre áreas e visão institucional mais geral e não só de sua especialidade. Estes 
cuidados são tomados porque esta não é uma avaliação de curso, mas sim uma avaliação mais global da instituição, considerando sua estrutura, dinâmica interna e relações comunitárias. Pelos feedbacks recebidos até aqui, de modo geral, esta composição revelou-se positiva para o processo e deve ser mantida nos próximos ciclos avaliativos: ter um consultor com formação em educação e outro com formação diversa, mas com experiência ampliada de vida acadêmica, sobretudo com experiência em gestão.

3. Realiza-se reunião com os consultores para explicar o processo, sua filosofia, seus objetivos, e discutir o roteiro de avaliação e levantar novas sugestões.

4. Cada dupla de consultores marca as datas de sua visita à instituição; após ter analisado o porttólio; os consultores são instruídos a entrevistar os dirigentes, professores, alunos, funcionários, a visitar instalações, laboratórios e biblioteca, a observar atividades didáticas ou extracurriculares, tentando formar uma idéia clara da dinâmica institucional e de seu papel na cidade e região, verificando as boas qualidades e problemas em face do contexto do Estado e da região.

5. Os especialistas fazem seus relatórios para o conselho, a partir de um roteiro básico de dados, com indicadores e observações qualitativas, com um parecer final e indicação de melhorias a serem buscadas pela instituição; esse parecer vai para a Câmara de Educação Superior, onde se designa um conselheiro para examinar e relatar a avaliação de uma instituição específica, e, esse conselheiro-relator apresenta seu parecer com sugestões à instituição, o qual é submetido à discussão e à aprovação da Câmara e, depois levado ao Conselho Pleno; quando a avaliação institucional apresenta problemas, é dado um prazo a ela para apresentar ao ConseIho um plano de superação das deficiências apontadas, que é acompanhado na continuidade do processo avaliativo e dos demais processos da instituição que tramitam no CEE (recredenciamento, reconhecimento de cursos, autorizações, etc.). Diligências e visitas também podem ser efetuadas.

6. É dado retorno à instituição, com envio do parecer aprovado em plenário, com as solicitações apontadas; estando a instituição em condições satisfatórias, os consultores e o relator recomendam, em geral, que ela dê um passo a mais.
7. Na seqüência dos ciclos de avaliação e dos processos de autorização, credenciamento, reconhecimento de cursos, o desempenho institucional, contextuado local e regionalmente é, a cada vez, considerado no compasso de suas melhorias (ou não) sucessivas.

A avaliação de que falamos é, pois, um processo que, pela sua concepção e forma de execução, procura contribuir para o aperfeiçoamento continuado das instituições, ou seja, para transformações institucionais relevantes. Não é um processo morto, ou dados que vão para a prateleira ou arquivo, ou para servir apenas à crítica ligeira. É um processo vivo e ativo a serviço das próprias instituições de ensino superior. A perspectiva desse processo avaliativo é essencialmente pedagógica, não uma perspectiva punitiva, mas orientadora. Espera-se, é evidente, por uma participação ativa das instituições na compreensão de seus problemas, tanto nas questões acadêmicas, quanto estruturais, e na busca de soluções, alternativas, novos caminhos, renovações, aperfeiçoamentos. Processos auto-avaliativos e avaliações externas podem contribuir para a reconstrução e renovação institucionais, no tempo, e também para contextos diversificados. Podem contribuir, sobretudo, para evitar a estagnação institucional e propiciar aperfeiçoamentos contínuos, mais consistentes e adequados a necessidades emergentes.

A idéia é ajudar a avançar, alavancar e não paralisar, fazer "involuir". Mas, mediante um acompanhamento sensato, continuado e dentro de uma política real de qualificação das instituições. Estamos vivendo em tempos exigentes; tenta-se, com este modelo avaliativo, dar uma contribuição, pois boa qualidade é o que será socialmente cada vez mais cobrado, aliás, direito de qualquer cidadão que adentre uma instituição de ensino superior. Esta avaliação está pensada até aqui, nestes termos.

Tem-se, pois, como objetivo, que o sistema de ensino superior, sob a jurisdição do CEE/SP, se qualifique cada vez mais, cuidando de seus processos de ensino, processos e modelos de estágios e da vivência com a pesquisa, conforme for o caso de suas vocações institucionais. Espera-se que esse processo avaliativo contribua para a dinamização das instituições de ensino superior que estão sob a
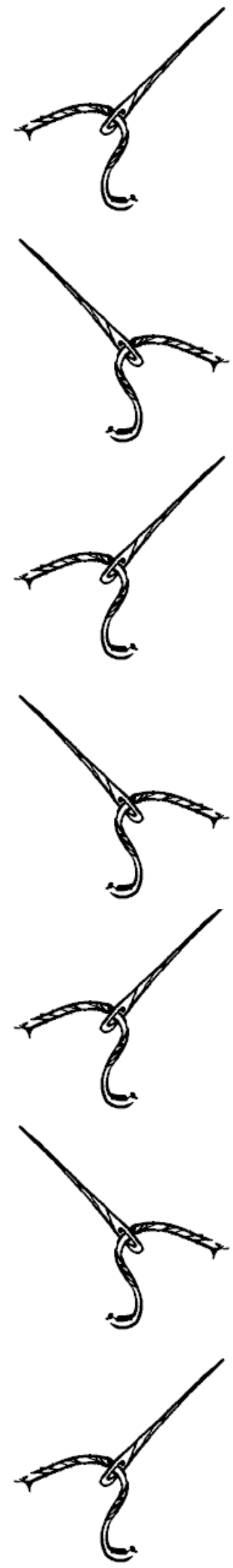
jurisdição do Conselho Estadual de Educação de São Paulo, especialmente mediante a apropriação pelas próprias instituições das análises que forem empreendidas, continuadamente.

\section{Avaliação das universidades e centros universitários}

O processo de avaliação proposto às instituições universitárias pertencentes ao sistema de ensino do Estado de São Paulo é definido como de caráter institucional, contínuo e permanente, um processo de avaliação interna, com a finalidade de analisar periodicamente o nível de desempenho e atualização institucional, especialmente quanto à eficácia de seu ensino e da formação profissional oferecida, à importância de seus programas de pesquisa, ao significado de suas ações comunitárias e à qualidade da gestão administrativa e financeira implementadas.

A metodologia da avaliação interna será estabelecida pela própria instituição e pode referir-se ao conjunto da instituição, às formas de gestão, ou dedicar-se sucessivamente a áreas ou conjuntos de departamentos ou unidades equivalentes, incorporando no processo órgãos complementares e setores equivalentes. É um processo a ser desenvolvido em três etapas: a) até um ano para o planejamento geral dos trabalhos de avaliação interna da instituição, para um período de cinco anos, com o respectivo cronograma; b) relatório parcial, ao término do terceiro ano, sobre os trabalhos já realizados; c) encaminhamento de relatório-geral no fim do quinto ano, com as conclusões. As instituições universitárias deverão submeter à avaliação interna a comissão ou comissões externas de pares, cujos relatórios deverão integrar os relatórios parciais ou finais, conforme o caso. Os relatórios finais encaminhados ao CEE/SP deverão ser apreciados por comissão de cinco especialistas indicados pela Câmara de Educação Superior do Conselho, alimentando o relatório de conselheiro-relator o qual será apreciado pela Câmara e pelo Pleno do Conselho e encaminhado à instituição com as recomendações. A avaliação interna qüinqüenal constituirá requisito fundamental no processo de recredenciamento junto ao CEE, bem como para reconhecimento dos cursos, inicial e periódico.

\section{Finalizando}

Nada é perfeito e definitivo. É consenso dos membros do CEE/SP que este processo deverá ser submetido continuamente, também, a uma avaliação consistente. Análises críticas, propostas, alternativas, transformações devem ser consideradas. O tempo dirá melhor de seu impacto e de suas contribuições.

\section{Recebido em 31 de março de 2000.}

Bernardete A. Gatti, doutora em Psicologia pela Université de Paris VII, com pósdoutorados na Pensilvannia University (USA) e Université de Montréal (Canadá), é coordenadora do Departamento de Pesquisas Educacionais da Fundação Carlos Chagas (FCC) e professora do setor de pós-graduação da Pontifícia Universidade Católica de São Paulo (PUC-SP), no Programa de Psicologia da Educação.

\section{Abstract}

This article calls the attention to some points related to the culture of evaluation in Brazil and to some basic features to be considered when developing an evaluative process. These processes are treated as a process of helping choices or changes. It emphasizes the social meaning associated to any process of this nature and the evaluator responsabilities. At last, it is presented an institutional research experiment that the State Council of Education of São Paulo is helding at the higher education institutions under its jurisdiction.

Key-words: higher education institution; institutional evaluation; evaluation model; São Paulo State Council of Education. 